\title{
Stem cell application in rotator cuff repair: Interposition stem cell sheet versus overlaid stem cell sheet
}

Jae hee Choi

Asan Institute for Life Sciences

Michael Seungcheol Kang

Asan Medical Center

Myung Jin Shin

Asan Medical Center

Dong Min Kim

Asan Medical Center

Yu Na Lee

Asan Institute for Life Sciences

In Kyoung Shim ( $\nabla$ shimiink@gmail.com )

Asan Institute for Life Sciences

Kyoung Hwan Koh ( $\nabla$ osdoc.koh@gmail.com )

Asan Medical Center https://orcid.org/0000-0002-6181-9621

\section{Research}

Keywords: engineered stem cell sheet, chronic rotator cuff, enthesis regeneration, delivery of stem cell

Posted Date: May 5th, 2020

DOI: https://doi.org/10.21203/rs.3.rs-25042/v1

License: (9) (i) This work is licensed under a Creative Commons Attribution 4.0 International License.

Read Full License 


\section{Abstract \\ Background}

Stem cells are an effective method of biologic healing and can be used to enhance the natural enthesis of the tendon-to-bone junction in rotator cuff repair. The purpose of this study was to investigate if the application of engineered stem cell sheets using adipose-derived cells (ADSCs) was effective in regeneration of natural enthesis and if there was a difference in the result of repair depending on the applied location

\section{Methods}

A chronic rotator cuff tear model was induced for 2 weeks, and cell sheets made using ADSCs isolated from rats were transplanted into the tendon-to-bone junction during surgical repair. Depending on the transplant location of the cell sheet, the difference in rotator cuff healing level between the overlaid group and the interposition group was compared to the surgical repair only group. The samples were obtained based on the tendon-to-bone junction and analysis of gross morphology, histology staining, and biomechanical analysis were performed.

\section{Results}

The differentiation potentials of ADSCs as stem cells were confirmed, as was the potential for tenogenic differentiation by growth factors. ADSCs were prepared as a sheet form to maintain the shape at the target site and to be easily attached. GFP-expressing ADSCs were proliferated in vivo and observed at the transplantation site. The overall healing level was better in the cell sheet transplanted group than in the control group that surgical repair only. Additionally, differences in healing level were shown depending on the cell sheet location by morphological, histological, and biomechanical perspectives. Histological results showed that the interposition transplantation group $(1.75 \pm 0.43, P=0.004)$ showed better fibrocartilage formation and collagen orientation at the junction than the overlaid transplantation group $(0.86 \pm 0.83)$.

\section{Conclusion}

In the chronic rotator cuff repair model, the engineered stem cell sheets enhanced the regeneration of the tendon-to-bone junction. This regeneration was more effective when the stem cell sheet was interpositioned at the tendon-to-bone interface.

\section{Trial registration:}




\section{Introduction}

The prevalence of the musculoskeletal disorders is increasing with the increase in the elderly population and participation in sports activities. These disorders not only cause physical pain but also have a considerable impact on social costs. In particular, rotator cuff tears, which can cause functional disorders in the shoulder, are common among tendon diseases. Despite the continued development of surgical treatment, there is still a high risk of re-rupture, which remains a clinically important issue $(1,2)$. The tendon is an elastic tissue composed of collagen that adheres to the bone, maintains movement, and transmits power. As such, the success of suture after rotator cuff tear depends on the recovery of the normal connection between the tendon tissue and the bone. Following rupture, the lesions are limited in their self-regeneration ability due to the relatively low cell density, distribution of blood vessels, and microenvironment changes. For this reason, surgical treatment tends to be followed by slow regeneration and incomplete recovery of the biological properties and original functions (3-5). To prevent re-tear after rotator cuff repair, many studies have reported on surgical techniques, fixation methods, and implant advancement to improve structural properties (6-9). Nevertheless, high re-rupture rates are still reported in large-to-massive tears, and a number of biological studies have been conducted to reduce the re-tear rate $(10,11)$.

Recently, as one of the methods for biologic healing enhancement, stem cell-based treatment has attracted attention as a means to improve the regeneration potential of tendon tissue (12-16). In particular, mesenchymal stem cells (MSCs) are widely used in tissue engineering because they are easy to separate and culture from various tissues. Indeed MSCs have been trialed variably as effective treatment methods for cell-based tendon regeneration research. However, a clear effect has not been demonstrated so far, and the success at the cellular level is limited for application to the preclinical or clinical stage. In terms of delivery, stem cells can be applied to lesions in various ways, such as injecting cells or injecting the culture medium of the cells to induce tissue regeneration $(13,15,17)$. However, this method is difficult to apply in a specific area and maintain for a long time. Moreover, it can also cause adhesion to surrounding tissues and the formation of scar tissue or ectopic bone, which eventually leads to poor quality of the damaged tendon tissue. However, by engineering stem cells in the form of a sheet, the stem cells can fairly easily adhere to the tissue and continuously function at the limited application site $(18,19)$. The purpose of this study was to determine the most effective delivery system for applying stem cells for biologic augmentation in rotator cuff repair. Among the different systems, we attempted to determine whether overlaying the cell sheet on the repair site or interposition to the tendon-to-bone junction was more effective for tendon-to-bone regeneration.

\section{Materials And Methods \\ Study design}


For the recovery of the tendon-to-bone junction, this experiment was divided into three groups to compare healing augmentation using stem cell sheets (Fig. 1). Four Sprague-Dawley (SD) rats were used for each group, and 8 samples per group were processed with the same treatment on both shoulders per rat. The chronic rotator cuff tear models were made identical in all groups as a suitable animal model for this experiment. In order to exclude the possibility of spontaneous healing from the rotator cuff tear in the rat, an initial tear was made and maintained for 2 weeks to create a model of chronic cuff tear $(20,21)$, before subsequently repairing. As a control, surgical repair was performed alone (Repair-only group), whereas the experimental group was divided into two groups according to the location of the stem cell sheet transplantation. In the first experimental group, after surgical repair, the stem cell sheet was overlaid on the repair site so that it covered parts of both the humerus and the tendon (Overlay group, 8 shoulders). In the second group, the stem cell sheet was first transplanted between the tendon and bone (greater tuberosity of humerus) in chronic tears, and then surgically repaired (Interposition group, 8 shoulders). After 2 weeks of repair, the repair quality was analyzed following sacrifice of all animals.

\section{Isolation and culture of primary ADSCs in SD rat inguinal fats}

Rat ADSCs were isolated from inguinal fat tissue of SD rats aged 8 weeks (Orient Bio, South Korea). In order to track the cell location after transplantation, the GFP-expressing ADSCs were isolated from SDGFP-transgenic rats (JapanSLC, Hamamatsu, JAPAN) and used to produce cell sheets. The ADSC isolation was performed using a previously published method (18). The inguinal fat tissue harvested from the rats was digested by $0.1 \%(\mathrm{w} / \mathrm{v})$ collagenase type I (Worthington, USA) dissolved in warmphosphate buffered saline (PBS, Welgene) for $1 \mathrm{~h}$ at $37^{\circ} \mathrm{C}$. The isolated rat ADSCs were cultured in Dulbecco's Modified Eagle Medium (DMEM) -low glucose medium (GIBCO, ThermoFisher Scientific, USA) containing $10 \%(\mathrm{v} / \mathrm{v})$ fetal bovine serum (FBS) and $1 \%$ antibiotic-antimycotic (A-A) solution in an incubator $\left(37^{\circ} \mathrm{C}, 5 \% \mathrm{CO}\right.$ ) . After incubation for $24 \mathrm{~h}$, the medium was changed to fresh culture medium. The cells were cultured up to passage 3 .

\section{Characterization of rat ADSCs}

\section{Flow cytometry analysis using surface makers}

To analyze MSCs surface markers, the rat ADSCs were seeded at passage 3 in 6-well plates (Nunc, Denmark). After $24 \mathrm{~h}$, the cells were incubated with antibodies for $1 \mathrm{~h}$ at $4{ }^{\circ} \mathrm{C}$ in darkness and washed twice in PBS. Flow cytometry (Cando, BD Bioscience, USA) analysis was performed, and the following antibodies were used: PE- isotype, PE-CD29, PE-CD31, PE-CD45, FITC-isotype, FITC-CD73 (BD, USA), FITCCD90 and MHC class I (AbD serotec, BIO-RAD, CA, USA).

\section{Confirmation of differentiation potential}

To confirm the adipogenic and osteogenic differentiation ability of the rat ADSCs, the cells were seeded in 6-well plates and incubated until there were approximately $5 \times 10^{5}$ cells/well. For adipogenic differentiation, the cells were incubated in adipogenesis medium (Gibco, Life Technologies, USA) for 2 
weeks. The cells were then stained with Oil red 0 solution (Sigma-Aldrich, USA) for 5 min. For osteogenic differentiation, the cells were incubated in DMEM-low glucose medium containing 1\% A-A, $10 \mathrm{nM}$ dexamethasone, $10 \mathrm{mM} \beta$-glycerophosphate, and $50 \mu \mathrm{M}$ ascorbic acid. After 4 weeks, the cells were stained with $2 \%(\mathrm{w} / \mathrm{v}$ ) Arizarin Red solution (Sigma-Aldrich, USA) for $30 \mathrm{~min}$.

\section{Immunocytochemistry}

Rat ADSCs were seeded at $1 \times 10^{5}$ cells/well in 24 -well plates for $24 \mathrm{~h}$. The cells were incubated in advanced-DMEM/F12 medium containing $2 \%$ FBS, $100 \mathrm{ng} / \mathrm{ml}$ growth differentiation factor-7 (GDF-7, R\&D system, MN), and $50 \mu \mathrm{g} / \mathrm{ml}$ ascorbic acid (Sigma-Aldrich, USA), and the medium was changed every 3 days. After 2 weeks, the cells were fixed with 4\% paraformaldehyde (Invitrogen, USA) for 30 min and blocked with $1 \%$ bovine serum albumin (CellNest, USA) for $1 \mathrm{~h}$. Fixed cells were incubated with tendonrelated antibodies, scleraxis and tenomodulin (abcam, UK), overnight at $4{ }^{\circ} \mathrm{C}$ at 1:500 dilution. Then, the cells were washed twice and incubated with a green fluorescence conjugated secondary antibody for 90 min. Nucleic acids were stained with Hochest 33342 (Invitrogen, USA) for 5 min.

\section{Quantification of genes by RT-qPCR}

The rat ADSCs were seeded at $2 \times 10^{5}$ cells/well in 6-well plates for $24 \mathrm{~h}$. The cells were incubated with GDF-7 in the same conditions as those used for immunocytochemistry. After 2 weeks, the treated cells were harvested and total RNA was extracted using TRIzol reagent (ThermoFisher Scientific, USA). RTqPCR was performed using SYBR ${ }^{\text {TM }}$ Green PCR Master Mix (applied biosystems, UK). Primers were prepared using sequences verified in previously published papers $(22,23)$; the sequences are summarized in Table 1. GAPDH was used for normalization. The gene expression levels were measured using an ABI prism 7900HT (applied biosystems) PCR machine, and the relative gene expression levels were quantified using $2^{-\Delta \Delta C t}$ values.

Table 1. Primer sequence information 


\begin{tabular}{|c|c|c|c|}
\hline Primer & GenBank file & & Sequence $\left(5^{\prime} \rightarrow 3^{\prime}\right)$ \\
\hline \multirow[t]{2}{*}{ Scleraxis } & \multirow[t]{2}{*}{ NM_00130508.1 } & Forward & TGGCCTCCAGCTACATTTCT \\
\hline & & Reverse & TGTCACGGTCTTTGCTCAAC \\
\hline \multirow[t]{2}{*}{ Tenomodulin } & \multirow[t]{2}{*}{ NM_022290.1 } & Forward & GGGATTGACCAGAATGAGCAA \\
\hline & & Reverse & GGTGCGGCGGGTCTTC \\
\hline \multirow[t]{2}{*}{ Tenascin C } & \multirow[t]{2}{*}{ XM_008763758.2 } & Forward & CAGAAGCCTTGGCCATGTG \\
\hline & & Reverse & GCACTCTCTCCССTGTGTAGGA \\
\hline \multirow[t]{2}{*}{ Collagen Type $\square$} & \multirow[t]{2}{*}{ NM_032085.1 } & Forward & TGATGGGATCCAATGAGGGAGA \\
\hline & & Reverse & GAGTCTCATGGCCTTGCGTGTTT \\
\hline \multirow[t]{2}{*}{ Collagen Type } & \multirow[t]{2}{*}{ NM_053304.1 } & Forward & GCCAAGAAGACATCCCTGAA \\
\hline & & Reverse & GCAGAAAGGACAGCACTCGC \\
\hline \multirow[t]{2}{*}{ GAPDH } & \multirow[t]{2}{*}{ XM_017592435.1 } & Forward & TCTCTGCTCCTCCCTGTTCTA \\
\hline & & Reverse & ATGAAGGGGTCGTTGATGGC \\
\hline
\end{tabular}

The above sequences were identified in the Primer-BLAST-NCBI.

\section{Cell sheet fabrication}

The rat ADSCs were seeded at passage 3 at $1.2 \times 10^{6}$ cells/dish in a temperature-responsive dish ( $35 \mathrm{~mm}$, ThermoFisher Scientific, USA), and incubated for $24 \mathrm{~h}$ at $37^{\circ} \mathrm{C}$. Then, the cells were removed from the dish by changing to a lower temperature of $20^{\circ} \mathrm{C}$ (Fig. 2A). The removed cells shrunk to form a small round sheet (19).

\section{Animal model}

\section{Chronic rotator cuff tear model}

Eight-week-old male SD rats with a weight of $250 \mathrm{~g}$ were used for this study. Prior to surgical treatment, $0.3 \mathrm{cc}$ of a mixed solution with $50 \mathrm{mg} / \mathrm{kg}$ of Tiletamine/zolazepam (Virbac, Carros, France) and $10 \mathrm{mg} / \mathrm{kg}$ of Xylazine (Bayer HealthCare, Leverkusen, Germany) was intramuscularly (IM) injected. First, 
the supraspinatus tendon (SSP) attached to the humerus head was cut as close to the footprint as possible. A plastic drain was used to block the spontaneous healing in both the torn tendon stump and the humeral greater tuberosity. In particular, a stump on the torn tendon side was sealed with the plastic drain using 5 - 0 Ethibond (Somerville, USA) to block spontaneous healing (Fig. 2B). 5 - 0 Vicryl and 4 - 0 Prolene (Somerville, USA) were used for muscle and skin suture, respectively. After making a tear on the supraspinatus tendon, the rats were maintained with free cage activity for 2 weeks. Thus, the rat model of the chronic tear was completed $(20,21)$. For the prevention of infection and pain relief, $50 \mathrm{mg} / \mathrm{kg}$ of ampicillin and $3 \mathrm{mg} / \mathrm{kg}$ of ketorolac were IM injected every day for 3 days after the tear model was created.

\section{Rotator cuff repair and cell sheet application}

All plastic drains were removed 2 weeks after the tear was made. The scar tissues around the tear were removed as much as possible and repair was performed. In the control group, repair-only, the greater tuberosity of humerus head was drilled with a $0.5 \mathrm{~mm}$ drill, and the isolated SSP was transosseous suture repaired using 5 - 0 Ethibond $(24,25)$. In the interposition group of the experimental group, a drill hole of greater tuberosity was made identically, 5 - 0 Ethibond was passed through to prepare a repair, and a stem cell sheet was applied. The prepared rat ADSC sheet was transferred on a tendon footprint of greater tuberosity using a thin membrane shifter (ThermoFisher, USA). In order to stably attach the sheet to the tissue, only the shifter was removed carefully after waiting for approximately 1 min (Fig. 3).

\section{Evaluation}

\section{Sampling}

Two weeks after repair, all animals in this study were sacrificed using carbon dioxide gas. Based on the tendon-to-bone junction on both shoulders, tissues were completely removed, with the exception of the humerus head and tendon part.

\section{Histological estimation}

We obtained 4- $\mu \mathrm{m}$ thick tissue sections through the following series of processes: Formalin fixation, paraffin embedding, deparaffinization, and dehydration with changed alcohol concentration. Immunohistochemistry staining was carried out using a GFP-antibody (Abcam, UK). The primary antibody was diluted at a 1:500 ratio. The procedures requiring DAB staining were performed by the pathology department. The sectioned tissues were stained with Hematoxylin and Eosin (H\&E) solution (Sigma-Aldrich, USA). To confirm of the presence of collagen fibers, the sectioned tissues were stained using Masson trichrome (MT) kit and Safranin O (SA) kit (Polysciences, Inc., USA). The images were taken using an EVOS microscope (ThermoFisher Scientific, USA).

The fibrocartilage region was analyzed by H\&E, Masson, and SA staining using four criteria: bone, tendon, mineralized fibrocartilage, and vascularity (Table 2). The results were scored by two independent observers and finally evaluated as the average value $(25,26)$. In particular, a sample stained with safranin 
O was observed under a microscope to evaluate the fibrocartilage formed by repair after tear was made. The fibrocartilage formation area was quantitatively analyzed using the ImageJ software program (National Institutes of Health, MD) based on the surgical site (27).

Table 2. Histological scoring system at the tendon-to-bone location

\begin{tabular}{|c|c|c|}
\hline \multicolumn{2}{|l|}{ Categories } & \multirow{2}{*}{$\begin{array}{l}\text { Scores } \\
2\end{array}$} \\
\hline Bone & Abundant & \\
\hline : Bone formation & Moderate & 1 \\
\hline : Architecture & Lack & 0 \\
\hline Tendon & Orientation (+) and Thickness (+) & 2 \\
\hline : Fiber orientation & Orientation $(+)$ or Thickness $(+)$ & 1 \\
\hline : Continuity & Orientation (-) and Thickness (-) & 0 \\
\hline Tendon-to-bone junction & Abundant (+) and Tidemark (+) & 2 \\
\hline : Fibrocartilage formation & Abundant (+) or Tidemark (+) & 1 \\
\hline : Tide mark & Abundant (-) and Tidemark (-) & 0 \\
\hline Vascularity & Abundant & 2 \\
\hline : Vascular formation around the tendon & Moderate & 1 \\
\hline & Lack & 0 \\
\hline Total scores & & $0-8$ \\
\hline
\end{tabular}

\section{Biomechanical comparisons}

A biomechanical test was performed using a machine capable of measuring the uniaxial tensile stress test (ST-1001; SALT, Korea). The proximal humerus side was fixed to the distal part of the machine using sandpaper, and the tendon side was fixed to the proximal part of the machine using a clamp. A gradient tension of $1 \mathrm{~mm} / \mathrm{min}$ was applied to measure the load to failure and stiffness $(28,29)$. 


\section{Statistical analysis}

Statistical analysis was performed using GraphPad Prism 5 (GraphPad Software, CA, USA). For comparison between groups, one-way analysis of variance (ANOVA) and post-hoc analysis were performed, and errors were corrected using Tukey's method. The data were presented as mean and standard deviation (SD). $P<0.05$ was considered as statistically significant, and $P<0.05$ was marked as * and $P<0.001$ as ** on the graph.

\section{Results}

\section{Properties of rat ADSCs}

Cell morphology, MSC-specific marker, and differentiation function were used to determine whether the stem cells isolated from 8-week-old SD rats can be defined as MSCs. Firstly, as a result of the cell morphology of rat ADSC sheet made using rat ADSCs cultured at passage 3 , it was confirmed through a microscope that the cells were attached and appeared in the fibroblast-like morphology (Fig. 4A, left). In addition, the rat ADSC-S were cultured to form a single layer in a round circle (Fig. 4A, right). Next, the rat ADSCs were found to be $99.9 \%, 100 \%$, and $99.9 \%$ positive for the MSC-specific surface markers CD 90 , CD29, and CD73, respectively. Moreover, ADSCs did not express CD45, CD31 (hematopoietic stem cell [HSC]), and MHC class I markers (Fig. 4B). To confirm osteogenic and adipogenic differentiation, ADSCs were cultured in differentiation medium and stained with oil red 0 and alizarin red. As a result, oil formation and calcium accumulation were confirmed (Fig. 4C). Thus, based on these results, it was found that rat ADSCs used in this study have potential activity as MSC.

Since GDF-7 is known to induce tenogenic differentiation (30-33), GDF-7 was additionally added to rat ADSCs. In immunocytochemistry, the fluorescence over-expression of differentiation was confirmed in scleraxis and tenomodulin, which are representative tendon-specific gene markers (Fig. 4D, upper). As a result of RT-qPCR, when the control values were normalized to 1 in each marker, the differentiation values were $5.18 \pm 1.24,2.9 \pm 0.87,2.05 \pm 0.28$, and $2.38 \pm 0.27$ in scleraxis, tenomodulin, tenascin-C, and collagen type III. Thus, the tenogenic differentiation potential of rat ADSC was confirmed with increases in the gene expression level (Fig. 4D, lower).

\section{Locations of transplanted rat ADSC sheet in vivo}

To confirm that the transplanted rat ADSC sheet was located and remained at the applied site, GFPfluorescence was detected in the cell sheet made from the rat ADSCs isolated from GFP-transgenic rats (Fig. 5A). When the cell sheet remained and GFP was overexpressed, it was stained with a brown dot and its location was confirmed. In the case of overlaid transplantation of cell sheets on repaired tendon-tobone junctions, it was confirmed that the brown spots were distributed outside the junction. On the other hand, when the sheet was transplanted in the tendon and bone interposition, fluorescence could be confirmed inside the junction. It was found that rat ADSC sheet was still present at the applied site 2 weeks after transplantation and could affect healing. 


\section{Effects of rat ADSC sheet on attachment locations \\ Gross morphology and histology}

After 2 weeks of repair, it was confirmed that the group transplanted with the rat ADSC sheet overlay had a higher amount of tissue in the region above the junction compared to the repair-only group.

Furthermore, the group transplanted with interposition demonstrated a hardened junction region and a relatively thickened SSP.

On histologic evaluation, the total score was significantly higher in the interposition group $(5.17 \pm 1.14)$ than in the repair group ( $3.21 \pm 1.42)$ and overlay group (3.29 \pm 1.87$)$. No bone formation or structural differences were observed in any of the three groups, and there was no statistically significant difference in tendon and blood vessel formation. However, the tendon-to-bone junction showed a significant difference $(P<0.05)$ in the interposition group compared to the other two groups. A considerable amount of fibrocartilage was formed, and the boundary at the mineralized fibrocartilage became clear in the two groups transplanted with the stem cell sheet. In particular, with Masson staining, it was found that the interposition transplanted group had a broader and more clearly formed collagen formation range and direction than the overlaid group (Fig. 5B, C). This was confirmed by quantifying the area of the redstained glycosaminoglycan region in safranin $\mathrm{O}$ staining and showing statistically significant differences between the groups (Fig. 5D).

\section{Biomechanical test}

The maximum load to failures were significantly different between the three groups, especially the repair group and the overlay group $(12.51 \pm 5.19 \mathrm{~N}$ and $17.02 \pm 5.32 \mathrm{~N})$, and the repair group and the interposition group $(12.51 \pm 5.19 \mathrm{~N}$ and $19.20 \pm 5.63 \mathrm{~N})$. In terms of stiffness, the repair group ( $5.00 \pm$ $1.07 \mathrm{~N} / \mathrm{mm})$ was significantly different compared to the interposition group $(9.89 \pm 0.83 \mathrm{~N} / \mathrm{mm})$. However, in the overlay group $(7.06 \pm 1.80 \mathrm{~N} / \mathrm{mm})$, the numerical value was increased, but there was no statistically significant difference (Fig. 6).

\section{Discussion}

The results of this study demonstrated that engineered stem cell sheets are an effective way to allow MSCs to act in sufficient quantities for a relatively long period of time. In addition, in the application method, it was shown that the interposition of the tendon-bone interface was more effective in the regeneration of the tendon-to-bone junction than the overlay.

It is known that scar tissue healing occurs mostly in the tendon-to-bone junctions, even in situations when rotator cuff tearing is performed. This is considered to explain the reason for early stage re-ruption of suture surgery. Therefore, many studies have attempted to overcome the limitation of scar tissue healing and recovery native enthesis. Among these, stem cells are getting attention on account of their paragenic effects, as well as their tenogenesis potential. However, it is difficult to fully determine whether these 
ADSCs have the capacity to augment healing $(34,35)$, and how to deliver these stem cells to the lesion remains under debate. Whether sufficient stem cells can be administered, whether the cells have high activity and viability, the extent to which the lesion can be reached, and how long the cells remain in the target region have not yet been studied adequately. The stem cell sheets applied in this study were able to supply a sufficient quantity of stem cells in a controlled manner while also maintaining cell activity. In addition, as a characteristic of engineering itself, it was easy to move to the application site using a cell shifter without a special adhesion method, and the cells appeared to stay at the application site for a relatively long time. Histological examination, confirmed by GFP expression, also showed that the stem cells remained at the applied site after 2 weeks. This compared to the stem cell injection method, stem cell delivery without worrying such as wash out. It was found that it is an effective method that can be applied (Fig. 5A).

One of the characteristic histological findings of native enthesis at the interface between the tendon and bone that we attempted to recover is the formation of an unmineralized and mineralized fibrocartilage layer. We demonstrated that stem cell sheets enhance regeneration with this native enthesis (Fig. 5B). Particularly, when the stem cells were interposition between the tendon and bone, an enthesis site, an increase in the fibrocartilage layer was apparent on the histological exam that showed statistically and substantially superior biomechanical properties. Even when the stem cell was overlaid on the adjacent part of the repair, fibrocartilage formation was abundant compared to the repair only; this result may be interpreted as a paracrine effect. However, with regards to interposition, it could be observed to a more robust fibrocartilage layer and collagen alignment, and this case can be said that not only the direct differentiation potential of the stem cells but also the possibility that the paracrine effect acts simultaneously.

This study had a limitation in that it is difficult to evaluate the mechanism of the effect of stem cells because the tendon-to-bone junction tissue could not directly track the tenogenic and adipo- or osteogenic differentiation of stem cells. In addition, although 8 shoulders were compared per group, the sample size was relatively small for both the histology and biomechanical tests. However, despite the sample size limitations, we were able to confirm the obvious histology and biomechanical statistical differences.

\section{Conclusion}

In this study, engineered stem cell sheets were shown to be effective for the recovery process of enthesis (tendon-to-bone junction) in a chronic rotator cuff repair rat model. In particular, we were able to demonstrate that the recovery effect was further improved when the stem cell sheet was interposition between the tendon and bone.

\section{Abbreviations}

ADSCs 
Adipose-derived cells

MSCs

Mesenchymal stem cells

SD

Sprague-Dawley

DMEM

Dulbecco's Modified Eagle Medium

FBS

Fetal bovine serum

A-A

Antibiotic-antimycotic

PBS

Phosphate buffered saline

GDF-7

Growth differentiation factor-7

IM

Intramuscularly

SSP

Supraspinatus tendon

H\&E

Hematoxylin and Eosin

MT

Masson trichrome

SA

Safranin 0

ANOVA

Analysis of variance

SD

Standard deviation

HSC

Hematopoietic stem cell

\section{Declarations}

\section{Ethics approval and consent to participate}

This study was approved by the institutional Animal Care and Use Committee (IACUC) at the design stage (IACUC 2019-02-183). The current animal care and experiment were followed by national and institutional ethical guidelines. 
Not applicable

\section{Availability of data and materials}

The data that support the findings of this study are available on request from the corresponding authors.

\section{Competing interests}

The authors declare that they have no competing interests.

\section{Funding}

This journal was supported by National Research Foundation of Korea Grant funded by the Korean Ministry of Education (No. 2018R1D1A1A0208602512) and the Asan Institute for Life Sciences, Asan Medical Center, Seoul, Korea (No. 2019IP-0810).

\section{Author's contributions}

Choi JH, Kang SC: Providing the research design, performed the experiments and collecting data, writing the manuscript.

Shin MJ, Kim DM, Lee YN: Data collection and analysis

Shim IK, Koh KH: Research concept and design, final manuscript approval

\section{Acknowledgements}

Not applicable

\section{References}

1. Morikawa D, Muench LN, Baldino JB, Kia C, Johnson J, Otto A, et al. Comparison of Preparation Techniques for Isolating Subacromial Bursa-Derived Cells as a Potential Augment for Rotator Cuff Repair. Arthroscopy: The Journal of Arthroscopic \& Related Surgery; 2019.

2. Yin Z, Guo J, Wu T-Y, Chen X, Xu L-L, Lin S-E, et al. Stepwise Differentiation of Mesenchymal Stem Cells Augments Tendon-Like Tissue Formation and Defect Repair In Vivo. Stem cells translational medicine. 2016;5(8):1106-16.

3. Ackermann PW, Li J, Finn A, Ahmed M, Kreicbergs A. Autonomic innervation of tendons, ligaments and joint capsules. A morphologic and quantitative study in the rat. J Orthop Res. 2001;19(3):372-8.

4. Benjamin M, Kaiser E, Milz S. Structure-function relationships in tendons: a review. J Anat. 2008;212(3):211-28.

5. Shaw HM, Benjamin M. Structure-function relationships of entheses in relation to mechanical load and exercise. Scand J Med Sci Sports. 2007;17(4):303-15. 
6. Kim KC, Shin HD, Lee W-Y, Yeon K-W, Han S-C. Clinical outcomes and repair integrity of arthroscopic rotator cuff repair using suture-bridge technique with or without medial tying: prospective comparative study. Journal of Orthopaedic Surgery Research. 2018;13(1):212.

7. Denard PJ, Burkhart SS. Techniques for managing poor quality tissue and bone during arthroscopic rotator cuff repair. Arthroscopy. 2011;27(10):1409-21.

8. Burkhart S, Hartzler R. Arthroscopic Rotator Cuff Repair: How to Avoid Retear. Arthroscopy - Journal of Arthroscopic Related Surgery. 2019;35:12-3.

9. Bedeir YH, Jimenez AE, Grawe BM. Recurrent tears of the rotator cuff: Effect of repair technique and management options. Orthop Rev (Pavia). 2018;10(2):7593-

10. Lorbach O, Baums M, Kostuj T, Pauly S, Scheibel M, Carr A, et al. Advances in biology and mechanics of rotator cuff repair. Sports Traumatology: Knee Surgery; 2015. p. 23.

11. Shimokobe H, Gotoh M, Honda H, Nakamura H, Mitsui Y, Kakuma T, et al. Risk factors for retear of large/massive rotator cuff tears after arthroscopic surgery: an analysis of tearing patterns. Journal of Orthopaedic Surgery Research. 2017;12(1):140.

12. Pietschmann MF, Frankewycz B, Schmitz P, Docheva D, Sievers B, Jansson V, et al. Comparison of tenocytes and mesenchymal stem cells seeded on biodegradable scaffolds in a full-size tendon defect model. J Mater Sci Mater Med. 2013;24(1):211-20.

13. Qin TW, Sun YL, Thoreson AR, Steinmann SP, Amadio PC, An KN, et al. Effect of mechanical stimulation on bone marrow stromal cell-seeded tendon slice constructs: a potential engineered tendon patch for rotator cuff repair. Biomaterials. 2015;51:43-50.

14. Peach MS, Ramos DM, James R, Morozowich NL, Mazzocca AD, Doty SB, et al. Engineered stem cell niche matrices for rotator cuff tendon regenerative engineering. PLoS One. 2017;12(4):e0174789.

15. Lui PPY. Stem cell technology for tendon regeneration: current status, challenges, and future research directions. Stem Cells Cloning. 2015;8:163-74.

16. Kishore V, Bullock W, Sun X, Van Dyke WS, Akkus O. Tenogenic differentiation of human MSCs induced by the topography of electrochemically aligned collagen threads. Biomaterials. 2012;33(7):2137-44.

17. Foolen J, Wunderli SL, Loerakker S, Snedeker JG. Tissue alignment enhances remodeling potential of tendon-derived cells - Lessons from a novel microtissue model of tendon scarring. Matrix Biol. 2018;65:14-29.

18. Pak S, Hwang SW, Shim IK, Bae SM, Ryu YM, Kim HB, et al. Endoscopic Transplantation of Mesenchymal Stem Cell Sheets in Experimental Colitis in Rats. Sci Rep. 2018;8(1):11314.

19. Kim SR, Yi HJ, Lee YN, Park JY, Hoffman RM, Okano T, et al. Engineered mesenchymal stem-cellsheets patches prevents postoperative pancreatic leakage in a rat model. Sci Rep. 2018;8(1):360.

20. Hashimoto E, Ochiai N, Kenmoku T, Sasaki Y, Yamaguchi T, Kijima T, et al. Macroscopic and histologic evaluation of a rat model of chronic rotator cuff tear. J Shoulder Elbow Surg. 2016;25(12):2025-33. 
21. Liu XN, Yang CJ, Kim JE, Du ZW, Ren M, Zhang W, et al. Enhanced Tendon-to-Bone Healing of Chronic Rotator Cuff Tears by Bone Marrow Aspirate Concentrate in a Rabbit Model. Clin Orthop Surg. 2018;10(1):99-110.

22. Dai L, Hu X, Zhang X, Zhu J, Zhang J, Fu X, et al. Different tenogenic differentiation capacities of different mesenchymal stem cells in the presence of BMP-12. Journal of Translational Medicine. 2015;13(1):200.

23. Peviani SM, Guzzoni V, Pinheiro-Dardis CM, Silva YPD, Fioravante ACR, Sagawa AH, et al. Regulation of extracellular matrix elements and sarcomerogenesis in response to different periods of passive stretching in the soleus muscle of rats. Sci Rep. 2018;8(1):9010.

24. Thangarajah T, Henshaw F, Sanghani-Kerai A, Lambert SM, Pendegrass CJ, Blunn GW. Supraspinatus detachment causes musculotendinous degeneration and a reduction in bone mineral density at the enthesis in a rat model of chronic rotator cuff degeneration. Shoulder Elbow. 2017;9(3):178-87.

25. Zhu M, Tay ML, Callon K, Tuari D, Zhao L, Dray M, et al. Overlay repair with a synthetic collagen scaffold improves the quality of healing in a rat rotator cuff repair model. J Shoulder Elbow Surg. 2019;28(5):949-58.

26. Font Tellado S, Balmayor ER, Van Griensven M. Strategies to engineer tendon/ligament-to-bone interface: Biomaterials, cells and growth factors. Adv Drug Deliv Rev. 2015;94:126-40.

27. Zhu Q, Ma Z, Li H, Wang H, He Y. Enhancement of rotator cuff tendon-bone healing using combined aligned electrospun fibrous membranes and kartogenin. RSC Advances. 2019;9(27):15582-92.

28. Ide J, Tokunaga T. Rotator cuff tendon-to-bone healing at 12 months after patch grafting of acellular dermal matrix in an animal model. J Orthop Sci. 2018;23(2):207-12.

29. Plate JF, Brown PJ, Walters J, Clark JA, Smith TL, Freehill MT, et al. Advanced age diminishes tendonto-bone healing in a rat model of rotator cuff repair. Am J Sports Med. 2014;42(4):859-68.

30. Lee JY, Zhou Z, Taub PJ, Ramcharan M, Li Y, Akinbiyi T, et al. BMP-12 treatment of adult mesenchymal stem cells in vitro augments tendon-like tissue formation and defect repair in vivo. PLoS One. 2011;6(3):e17531.

31. Ni M, Rui Y, Chen Q, Wang Y, Li G. Effect of growth differentiation factor 7 on tenogenic differentiation of bone marrow mesenchymal stem cells of rat in vitro. Zhongguo Xiu Fu Chong Jian Wai Ke Za Zhi. 2011;25(9):1103-9.

32. Liu J, Tao X, Chen L, Han W, Zhou Y, Tang K. CTGF positively regulates BMP12 induced tenogenic differentiation of tendon stem cells and signaling. Cell Physiol Biochem. 2015;35(5):1831-45.

33. Gelberman RH, Linderman SW, Jayaram R, Dikina AD, Sakiyama-Elbert S, Alsberg E, et al. Combined Administration of ASCs and BMP-12 Promotes an M2 Macrophage Phenotype and Enhances Tendon Healing. Clin Orthop Relat Res. 2017;475(9):2318-31.

34. van Dongen J, Harmsen M, Van der Lei B, Stevens H. Augmentation of Dermal Wound Healing by Adipose Tissue-Derived Stromal Cells (ASC). Bioengineering. 2018;5:91.

35. Yoshida Y, Matsubara H, Fang X, Hayashi K, Nomura I, Ugaji S, et al. Adipose-derived stem cell sheets accelerate bone healing in rat femoral defects. PLoS One. 2019;14(3):e0214488-e. 


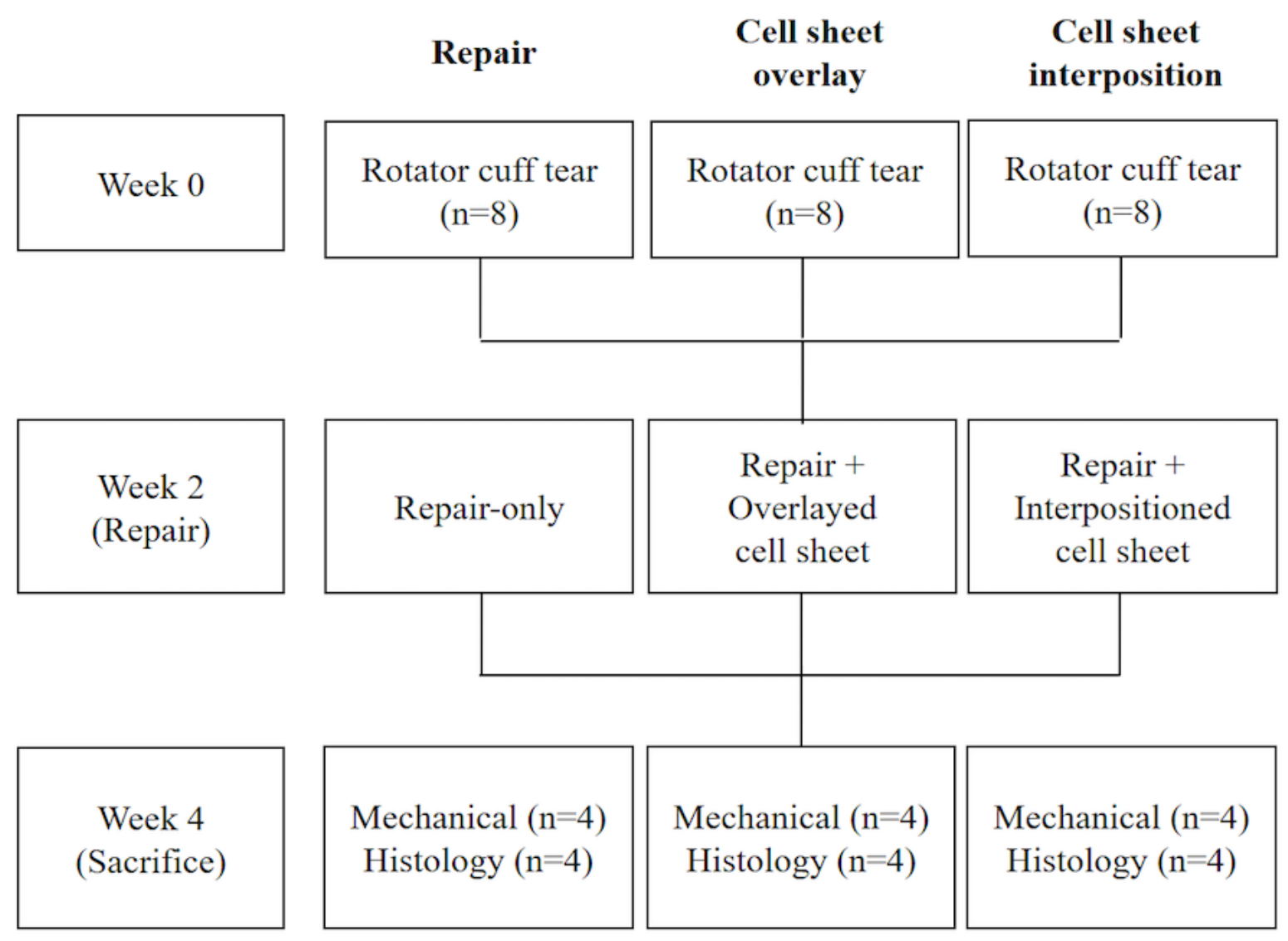

Figure 1

Animal experiment design. The experiment was divided into three groups, with 8 rats in each group 
A

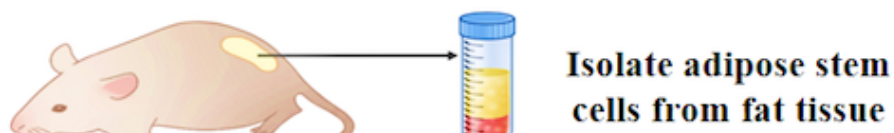

B
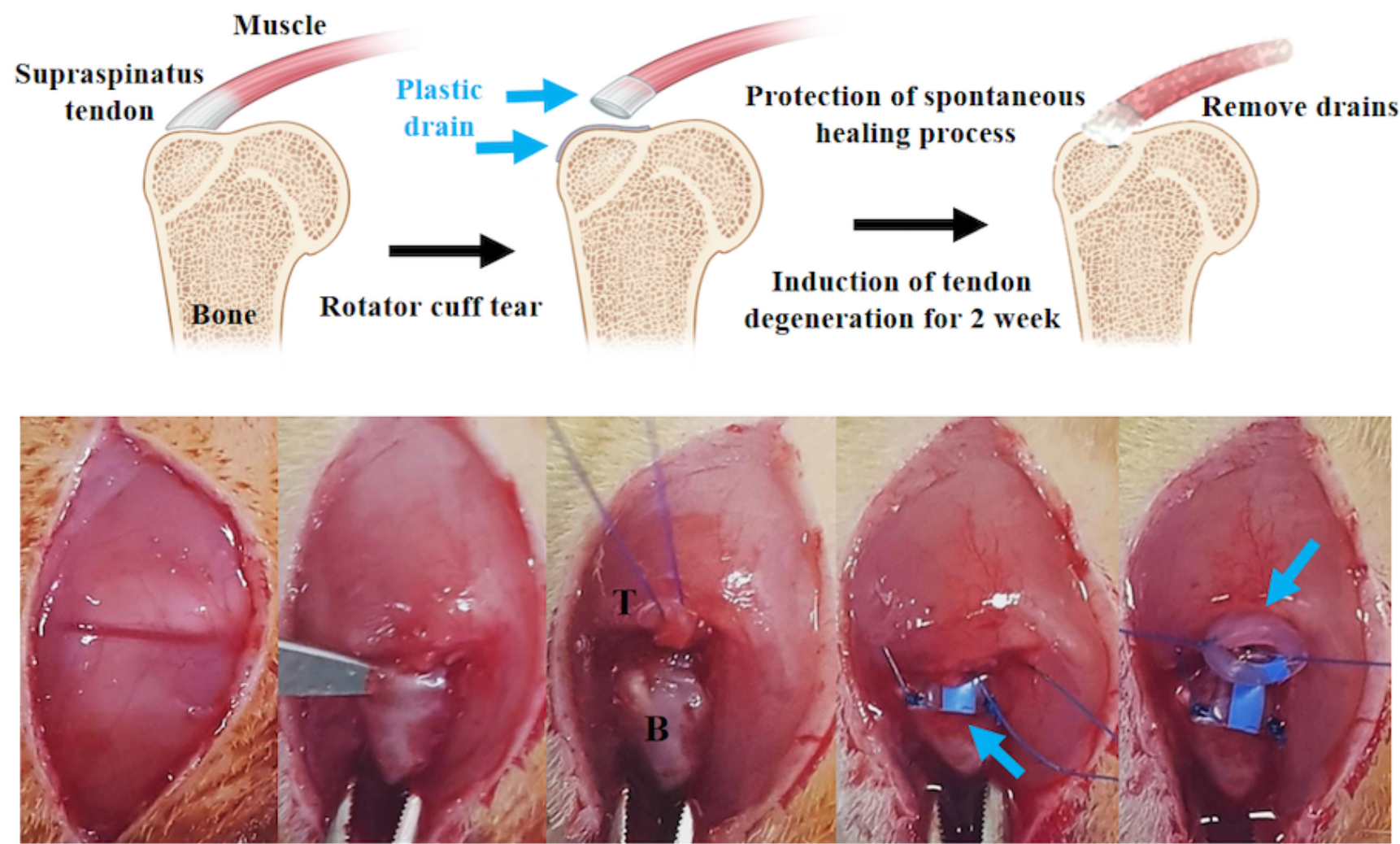

\section{Figure 2}

Schematic illustrations of cell sheets for regeneration after rotator cuff tear repair. (A) The concept of producing a cell sheet with adipose derived stem cells isolated from rats. The sheets were harvested by changing the hydrophilicity of the surface of the dish and decreasing the temperature. (B) The process of creating a chronic rotator cuff tear model. The tendons were completely separated and maintained for 2 weeks using a plastic drain in two places. T: Tendon, B: Bone, Blue arrow: Plastic drain. 


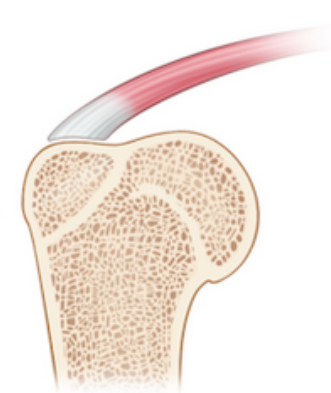

Repair only

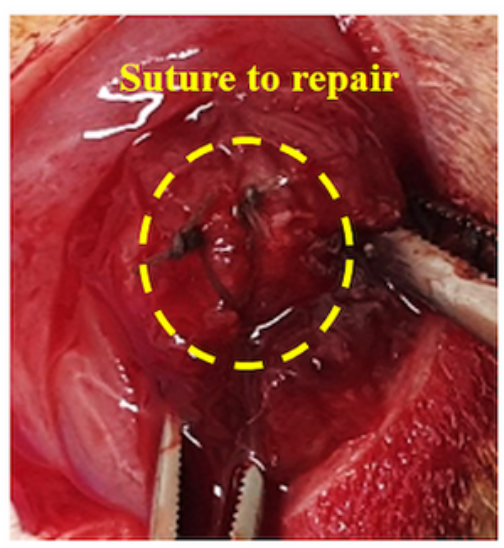

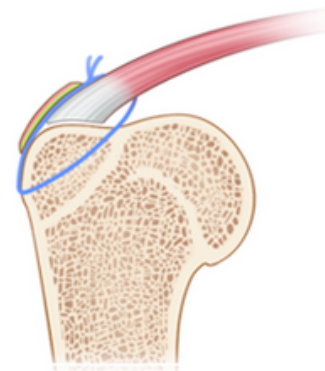

Cell sheet overlay

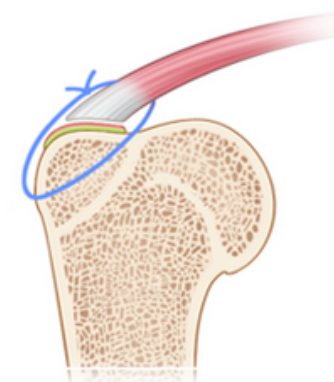

Cell sheet interposition
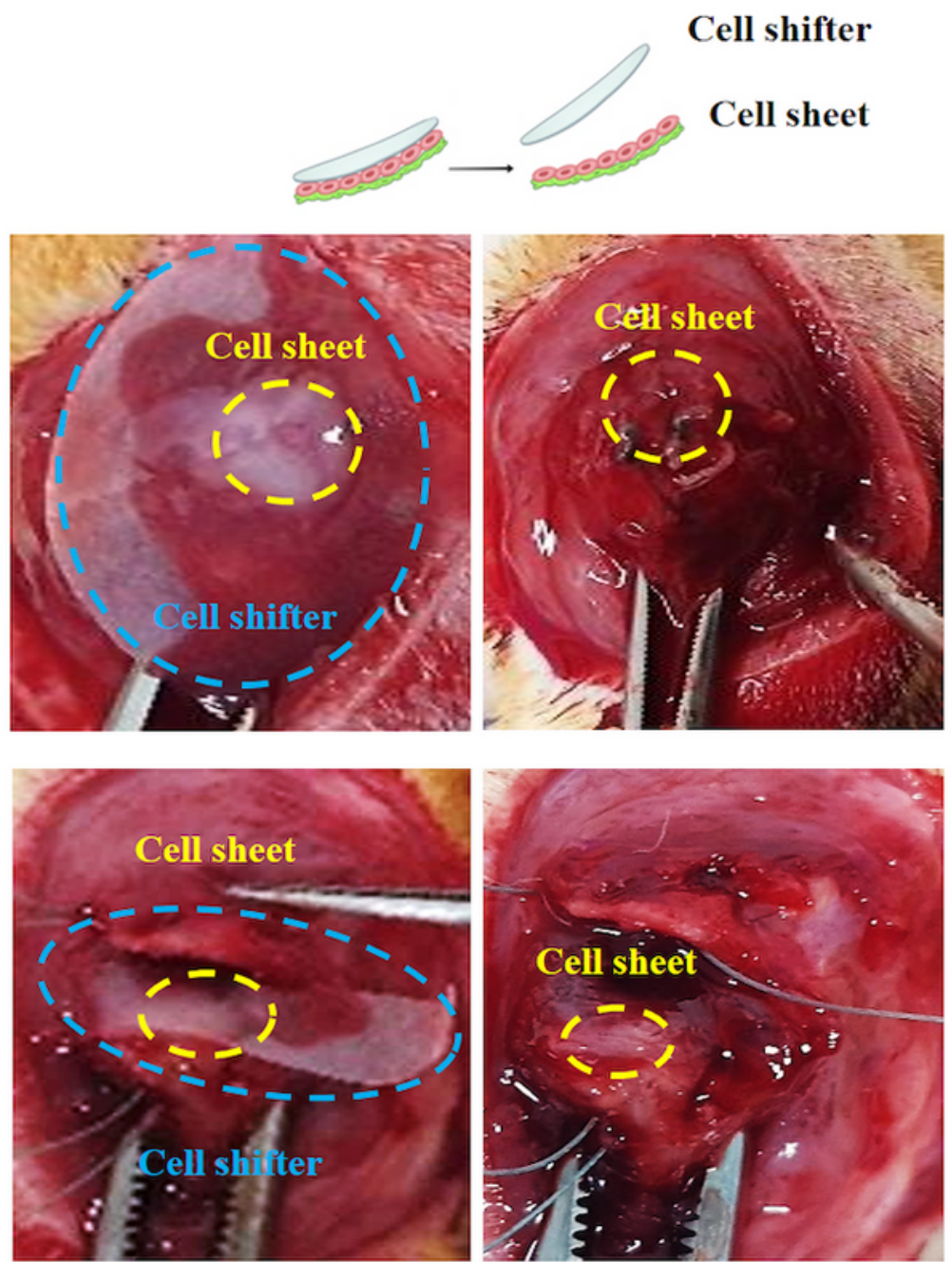

\section{Figure 3}

The formation of repair and cell sheet transplantation. The comparison of cell sheet transplantation among the three groups. Control group: Repair only, Experiment group: Cell sheet transplantation on top of the repair site or between tendon and bone. 
A
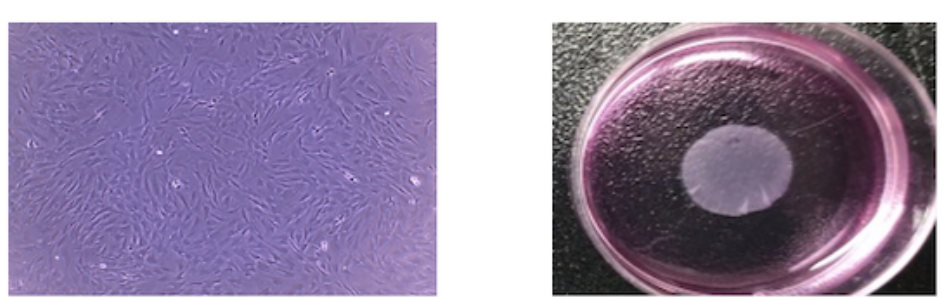

B

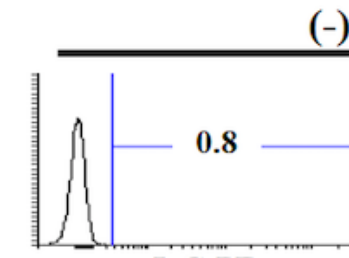

IgG-PE
$(-)$ con

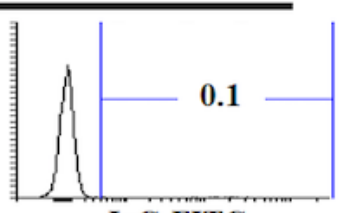

IgG-FITC

MSCs markers

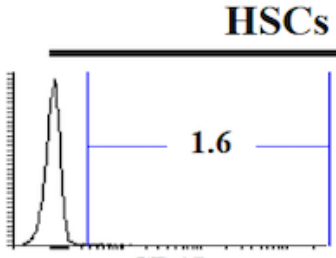

CD45
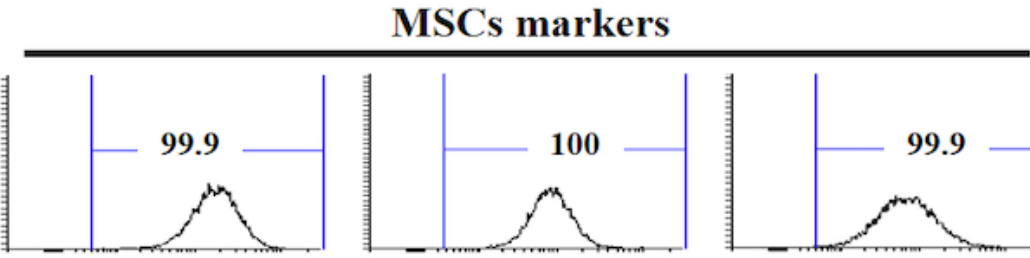

CD90

C

블

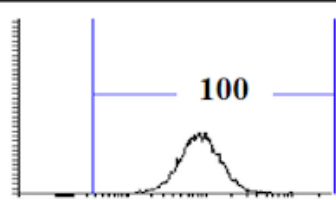

CD29

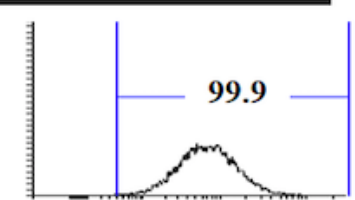

CD73

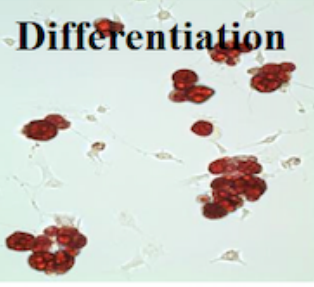

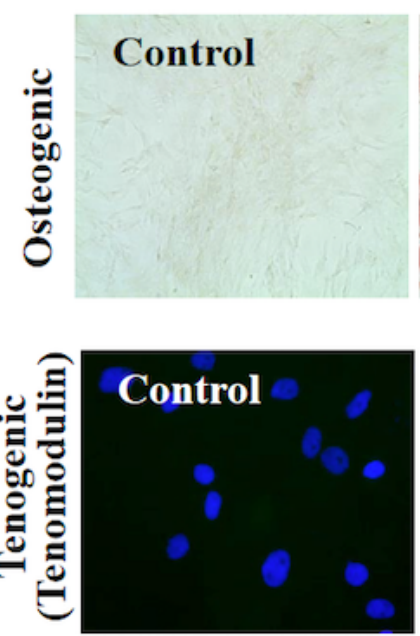

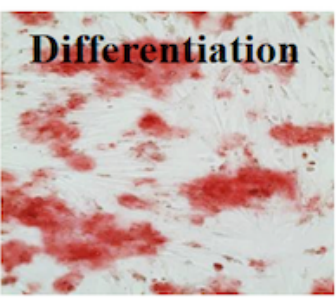

D
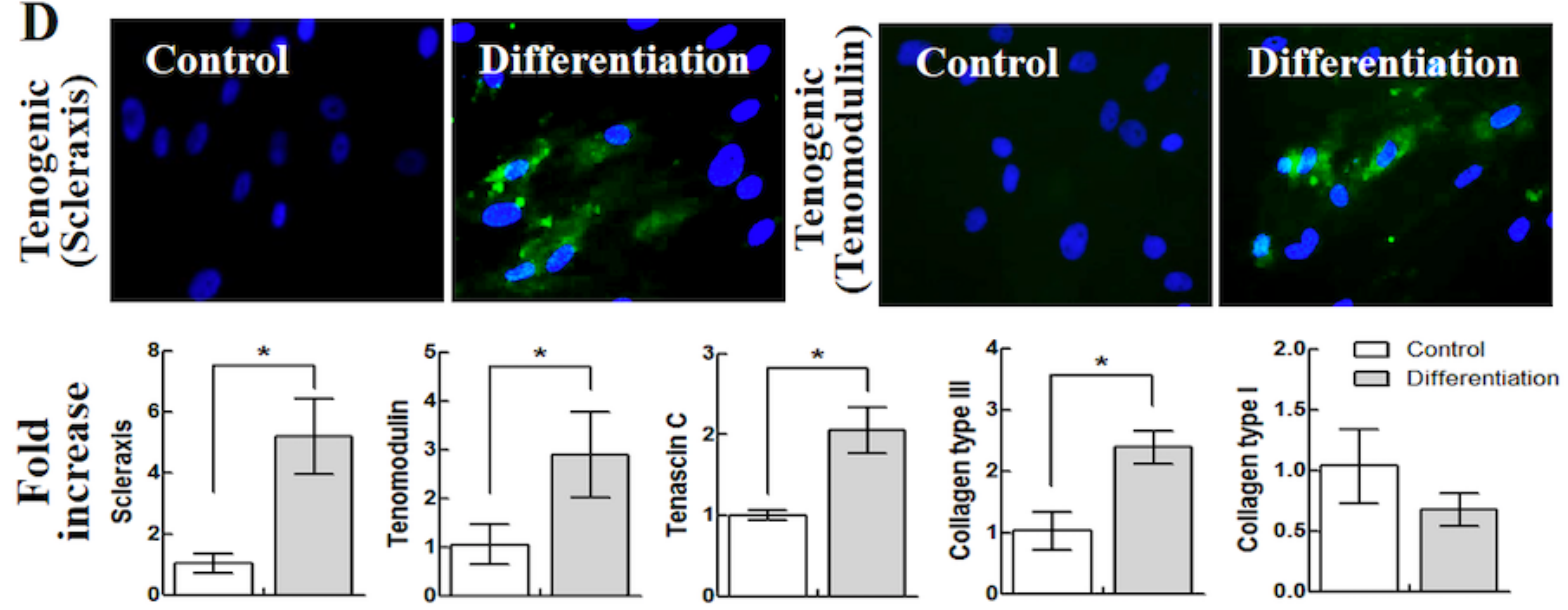

\section{Figure 4}

Characterization of rat ADSCs. (A) The morphology of the cell sheet with plastic adhesion (left) and the shape of the shrunken cell sheet (right). (B) The expression of MSC markers in rat ADSCs. (C) The differentiation potential of rat ADSCs into adipogenic and osteogenic formation. The differentiation sites were shown in red. (D) The tenogenic differentiation potential of rat ADSCs with GDF-7 treatment. The fluorescence images of tendon markers in rat ADSCs (upper). Green: Differentiated cells, Blue: Nuclei 
acid. The gene expression level of representative tendon markers in the cells $(n=3)$ (lower). Error bars represent $\mathrm{SD} .{ }^{*} \mathrm{P}<0.05$.

A

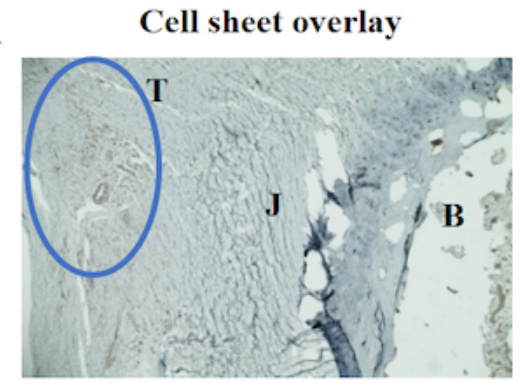

Cell sheet interposition

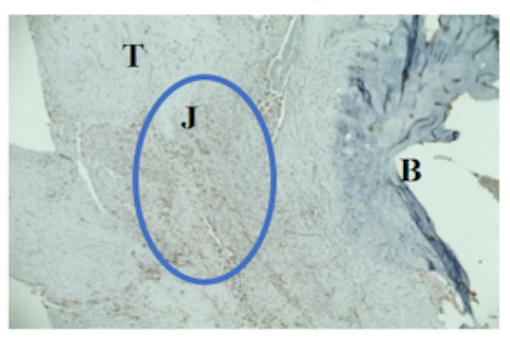

B
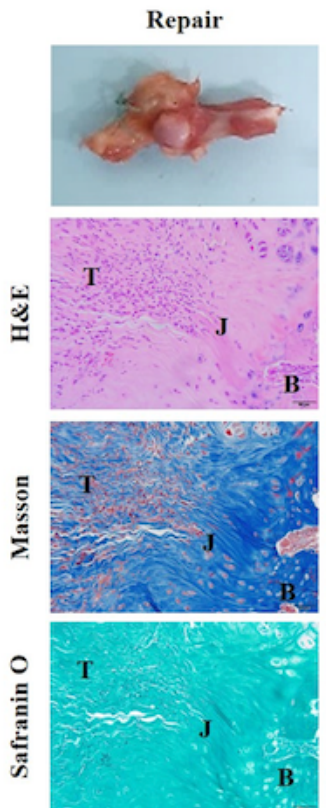

Cell sheet overlay

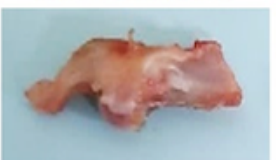

Cell sheet interposition
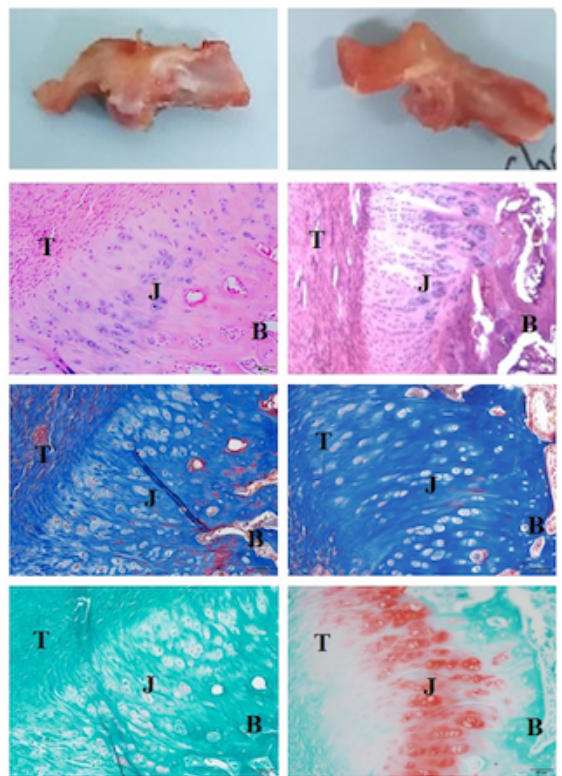
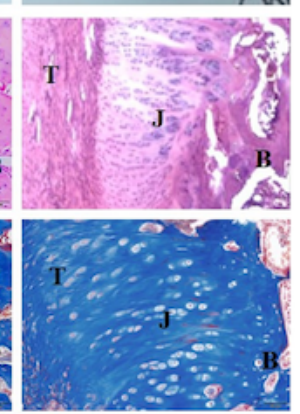

$\mathbf{T}$
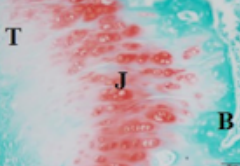

C

\begin{tabular}{|lcccc|}
\hline & Repair & $\begin{array}{c}\text { Cell sheet } \\
\text { overlay }\end{array}$ & $\begin{array}{c}\text { Cell sheet } \\
\text { interposition }\end{array}$ & $\begin{array}{c}\text { ANOVA } \\
\text { P-value }\end{array}$ \\
\hline Bone & $1.21 \pm 0.41$ & $1.14 \pm 0.64$ & $1.33 \pm 0.47$ & $\mathrm{P}=0.668$ \\
Tendon & $0.93 \pm 0.59$ & $0.93 \pm 0.70$ & $1.42 \pm 0.64$ & $\mathrm{P}=0.124$ \\
Tendon-to-bone junction & $0.79 \pm 0.77^{\mathrm{c}}$ & $0.86 \pm 0.83^{\mathrm{c}}$ & $1.75 \pm 0.43^{\mathrm{a}, \mathrm{b}}$ & $\mathrm{P}=0.004$ \\
Vascularity & $0.29 \pm 0.45^{\mathrm{c}}$ & $0.36 \pm 0.48^{\mathrm{c}}$ & $0.67 \pm 0.47$ & $\mathrm{P}=0.126$ \\
\hline Total scores & $3.21 \pm 1.42^{\mathrm{c}}$ & $3.29 \pm 1.87^{\mathrm{c}}$ & $5.17 \pm 1.14^{\mathrm{a}, \mathrm{b}}$ & $\mathrm{P}=0.005$ \\
\hline
\end{tabular}

${ }^{\mathrm{a}}$ Statistically significant change compared with repair group

${ }^{\mathrm{b}}$ Statistically significant change compared with overlay group

D

${ }^{\mathrm{c}}$ Statistically significant change compared with interposition group

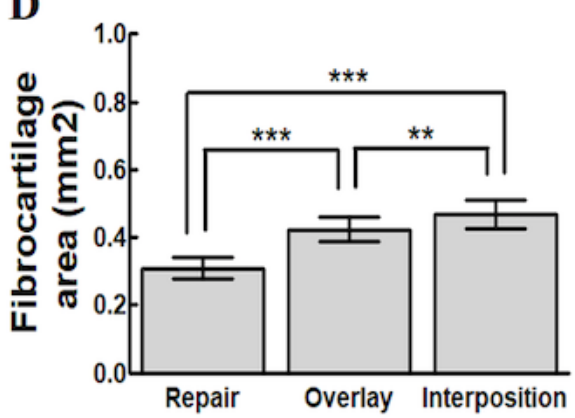

\section{Figure 5}

Histological analysis according to the application of the cell sheets after repair. (A) The confirmation of GFP expression depends on the location of the transplanted cell sheets. The cell sheets were transplanted above (left) or between (right) the tendon-to-bone junction. GFP expression was located at the blue circles 
and shown as brown dots. (B) The different gross morphology depends on the location of the transplanted cell sheets and histological representation of tendon-to-bone junction. T: Tendon, J: Junction, B: Bone. The size bars are $200 \mu \mathrm{m}$. (C) Histological scoring between the three groups were evaluated on four criteria. Statistically significant relationships between groups are indicated by the above subscript $(n=14)$. (D) Graph quantifying the relative fibrocartilage formation thickness at the tendon-to-bone junction. Error bars represent SD. ${ }^{*} P<0.01,{ }^{*} * * P<0.001(n=4)$.
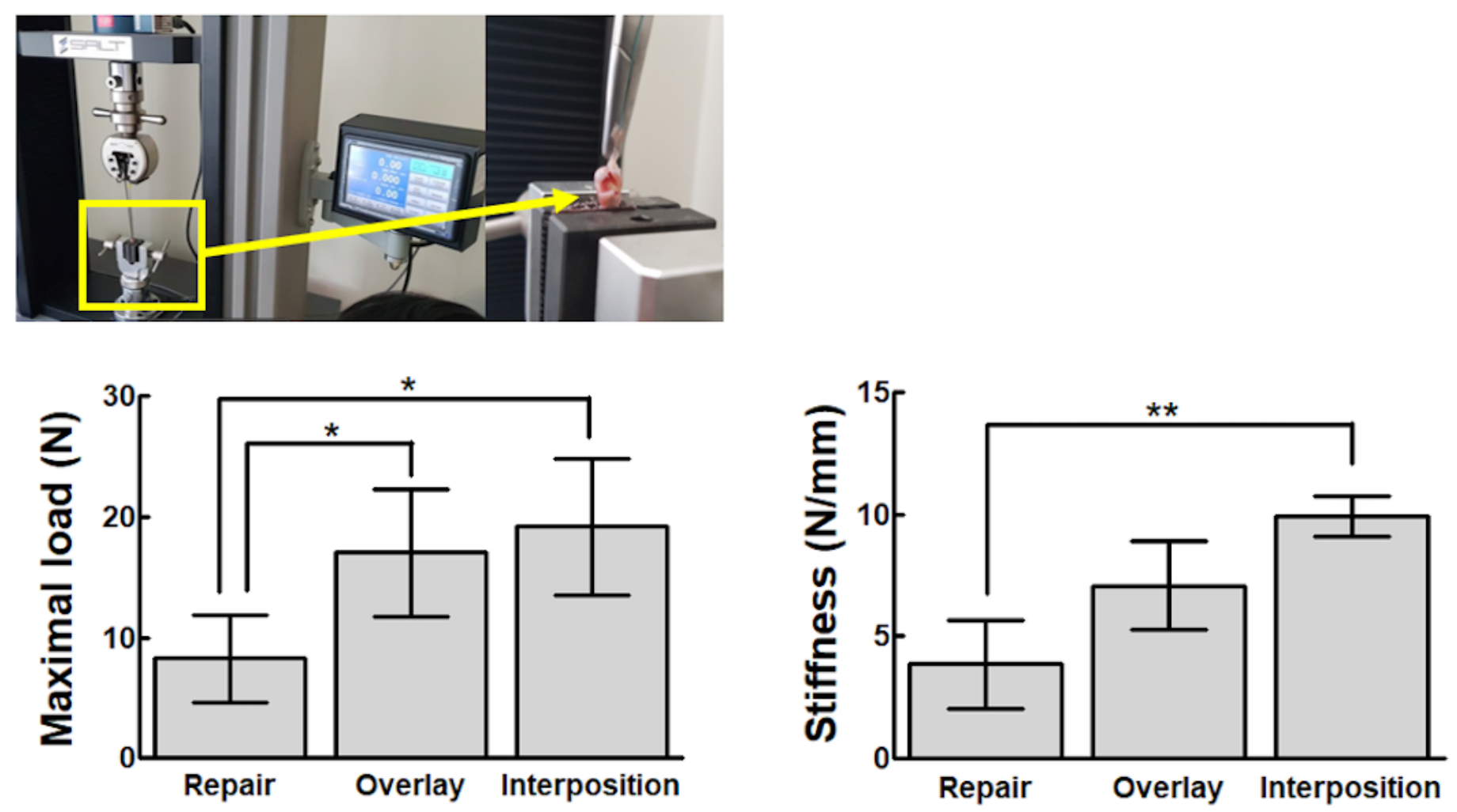

Figure 6

Biomechanical analysis of the application of cell sheets. Tensile test device (upper). Graphs indicating the maximal load and stiffness of the tendon-to-bone junction (lower). Error bars represent SD. ${ }^{*} P<0.05$, $\star * P<0.01(n=4)$. 